\title{
La evolución del recuerdo en Proust*
}

\author{
B. Novales Cinca**
}

Uno de los grandes problemas de Marcel Proust y sobre el que gira toda su obra, es establecer una relación entre el mundo onírico y el mundo de la realidad.

Para obtener una identificación entre el presente y el pasado, intenta todos los medios posibles, tomando como punto de partida el hombre en el momento presente.

Considero que este proceso evolutivo lo realiza Proust en tres fases, intimamente relacionadas, hasta llegar a una meta totalmente positiva. Estas fases son: la memoria voluntaria, la sensación y la memoria involuntaria.

Proust con ayuda de la memoria quiere encontrar los recuerdos que se hallan en el subconsciente; busca sin tregua los momentos de una infancia privilegiada, recuerdos fijados para siempre, explicaciones de variadas sensaciones, todo ello de una forma consciente, racional, es lo que el escritor llama «Memoria Voluntaria o de la Inteligencia».

«Mais comme ce que je m'en serais rappelé m'eût été fourni seulement par la mémoire volontaire, la mémoire de l'intelligence, et comme les renseignements qu'elle donne sur le passé ne conservent rien de lui, tout cela était en réalité mort pour moi» ${ }^{1}$.

El autor deposita en ella toda su confianza, cree poseer los medios de traer el recuerdo, pero poco a poco se da cuenta de que no es factible.

\footnotetext{
* El presente trabajo constituye un resumen de uno de los capítulos de la tesis de licenciatura leída por la autora en la Universidad de Zaragoza, 1975.

* Dpto. de Filología Francesa. Colegio Universitario de Logroño.

1. (Du côté de chez Swan». (A la recherche du temps perdu I.) Edit. Galli. mard. 1954, p. 54.
} 
«Mais il se débat trop loin, très confusement, à peine si je perçois le reflet neutre où se confond l'insaisissable tourbillon des couleurs remuées» ${ }^{2}$.

No obstante, no cesa en su empeño y quiere trabajar con ella, pues piensa que puede ser importante en la conquista del olvido.

Su desolación es extraordinaria al hacer trabajar su memoria voluntaria para que los recuerdos no se escapen como tantos otros, y comprobar su fracaso. Los ejemplos a lo largo de su obra son múltiples.

«Je rétrograde par la pensée au moment où je pris la première cuillère de thé... Je demande à mon esprit un effort de plus, de ramener encore une fois la sensation qui s'enfouit... Mais sentant mon esprit qui se fatigue sans réussir... Je fais le vide devant lui, je remes en face de lui la saveur encore récente de cette première gorgée et je sens tressaillir en moi quelque chose qui se déplace, voudrait s'élever, quelque chose qu'on aurait desancré à une grande profondeur» ${ }^{3}$.

«Chaque fois que le miracle d'une analogie m'avait fait échapper au présent. Seul, il avait le pouvoir de me faire retrouver les jours anciens, le temps perdu, devant quoi, les efforts de la mémoire et de mon intelligence échouaient toujours» ${ }^{4}$.

Esta intensa búsqueda del «Paradis Perdu», tendrá como consecuencia inmediata una gran decepción. En estos momentos, todos los impulsos, antes progresivos, vitalistas, se convertirán en regresivos, encontrándo en ellos la unidad de su obra.

Por todo lo cual Marcel Proust prefiere vivir en un mundo de ensueño, siempre maravilloso. La oscuridad de su habitación es un sedante, le aisla de la realidad, le sirve para hablar con Genoveva de Brabante, Golo, etcétera. Estas situaciones continuarán a lo largo de su vida, como un compañero fiel en el que Proust podrá refugiarse en los momentos más desagradables.

De una manera inconsciente el narrador siente aversión por partida doble, hacia el futuro, ya que no respeta el mundo de los sueños; hacia el presente, pues no le produce ninguna satisfacción.

¿Cómo encontrar el pasado gracias al recuerdo? Proust lo intenta por medio de las cosas, los objetos, pero este proceso tampoco es completo. No

2. Ibidem, p. 56 .

3. Ibidem, p. 56.

4. "Le temps retrouvé.» (A la recherche du temps perdu VIII.) Gallimard, 1954, p. 227. 
puede obtener con claridad el recuerdo, que se queda a mitad de camino entre el pasado y el presente. Para él es importante que el propio ser quiera tener recuerdos, es decir, tener predisposición. El niño que hace un drama cuando su madre no sube a darle el beso de despedida por la noche, conservará su alma sensible durante toda su vida.

«J'aurais voulu ne pas penser aux heures d'angoisse que je passerais ce soir seul dans ma chambre sans pouvoir m'endormir...» 5

Su temperamento hipersensible se siente atraido por las cosas y por la Naturaleza.

«A ce moment, je sentis comme une tendresse qui m'entourait. C'était l'odeur du lilas que dans mon exaltation j'avais cessé de percevoír et qui venait à moi» *

$Y$ así los momentos de angustia son superados por sensaciones que van apareciendo al azar. Son sensaciones de todo tipo: un rayo de sol, el ruido de un martillo, un olor, una música, un objeto. En un momento dado cualquiera de estas cosas producen «el choc» que mantiene al autor atento a que el instante maravilloso de recordar se produzca, pero no van más allá de un placer momentáneo. Estas sensaciones no le traen el recuerdo perdido y desaparecen después de una breve resurrección.

«J'essayais de me souvenir. Je voyais des guêpes dans un rayon de soleil, une odeur de cerises sur la table, je ne pus pas me souvenir... J'hésitais à la fois entre toutes les sensations confuses, connues ou oubliés de ma vie... Bientôt je ne vis plus rien, mon souvenir s'était à jamais rendormi» ${ }^{7}$.

El esquema de la sensación sería:

Angustia $\longrightarrow$ Naturaleza $\longrightarrow$ Sensación $\rightarrow$ Felicidad (momentánea)

«...et aussi parce qu'ils avaient l'air de cacher, au-delà de ce que je voyais quelque chose qu'ils invitaient à venir prendre et que malgré mes efforts je n'arrivais pas à découvrir, je restais là... à tâcher d'aller avec ma pensée au delà de l'image ou de l'odeur... Mais du moins elles me donnaient un plaisir irraison-

5. «Du côté de chez Swan.» (A la recherche du temps perdu I.) Gallimard, 1954, p. 30 .

6. "Contre Sainte-Beuve.) N.R.F. Edit. Idées-Gallimard, 1954, p. 70.

7. Ibidem, p. 60 . 
né... ces impressions de forme, de parfum ou de couleur, de tâcher d'apercevoir ce qui se cachait derrière elles...» ${ }^{8}$.

Este mecanismo le produce intensas sensaciones debido a su predisposición y a las circunstancias.

«...En constatant, en notant la forme de leur flèche, le déplacement de leurs lignes, l'ensoleillement de leur surface, je sentais que je n'allais pas au bout de mon impression, que quelque chose était derrière ce mouvement derrière cette clarté, quelque chose qu'ils semblaient contenir et dérober à la fois... Je ne savais pas la raison du plaisir que j'avais eu à les apercevoir à l'horizon et l'obligation de chercher à decouvrir cette raison me semblait bien pénible...» ${ }^{9}$.

Pero todo ello no pasará de ser una mera impresión. Indirectamente presentimos la fusión del pasado con el presente. Es el problema del «déjà vu».

«Je revenais devant les aubépines comme devant ces chefsd'oeuvre, dont on croit qu'on saura mieux les voir... mais $j$ 'avais beau me faire un écran de mes mains pour n'avoir qu'elles sous les yeux, le sentiment qu'elles éveillaient en moi restait obscur et vague, cherchant en vain à se dégager, à venir adhérer à leurs fleurs. Elles ne m'aidaient pas à l'éclaircir et je ne pouvais demander à d'autres fleurs de le satisfaire» ${ }^{10}$.

Estas impresiones se mueven dentro de dos mundos: el interior y el exterior. Este, se nos da por medio de sensaciones producidas por objetos. Para Proust la substancia es importante, ya que guarda la esencia del recuerdo. El problema es establecer un lazo de unión entre el objeto exterior y lo que guarda en su interior, e incluso discernir entre si los momentos de felicidad pertenecen al mundo de los sueños o si son una impresión ya vivida.

«...Parfois ce morceau de paysage amené ainsi jusqu'à aujourd'hui se détache si isolé de tout, qu'il flotte incertain dans ma pensée... sans que je puisse dire de quel pays, de quel temps... il vient» ${ }^{11}$.

8. «Du côté de chez Swan.» (A la recherche du temps perdu I.) Gallimard, 1954, pp. 214-215.

9. Ibidem, p. 216.

10. Ibidem, p. 167.

11. Ibidem, p. 221. 
El esquema podría ser :

Objeto $\longrightarrow$ Impresion $\longrightarrow$ Yo $\longrightarrow$ Souvenir (Quelque fois).

Mas a veces el momento del pasado aparece y no es correspondido con el presente.

Una impresión importante es la Sonata de Vinteuil.

«L'année précédente dans une soirée, il avait entendu une oeuvre musicale exécutée au piano et au violon... D'abord il n'avait goûté que la qualité materielle des sons... Mais à un moment donné, sans pouvoir nettement distinguer un contour... il avait cherché à recueillir la phrase où l'harmonie qui passait et qui lui avait ouvert larguement l'âme, come certains odeurs de roses...» ${ }^{12}$.

Este momento le hace reflexionar mucho tiempo, puesto que quiere descubrir lo que hay en su interior, pero siempre a partir de la inteligencia, lo que le llevará al más tremendo fracaso. Así este episodio queda reducido a una impresión fonética cuyo sentido no encontrará hasta el final de su vida.

Por esto, la sensación es un medio imperfecto a la hora de recordar, nunca le proporciona la felicidad del recuerdo completo.

Las sensaciones comienzan a tener un sentido para Proust cuando en ellas puede encontrar el pasado que guarda la felicidad.

Poco a poco el autor se rodea de un ambiente propicio al recuerdo.

El mecanismo es el mismo que en la memoria voluntaria, pero ahora todo se desarrolla en el interior del autor.

En un momento inesperado una sensación cualquiera, va a tener una resonancia en su interior que involuntariamente va a traerle recuerdos pasados.

«Quand un jour d'hiver, comme je rentrais à la maison, ma mère, voyant que j'avais froid me proposa de me faire prendre, contre mon habitude un peu de thé... Elle envoya chercher un de ces gâteaux courts et dodus appelés Petites Madeleines qui semblent avoir été moulés dans la valve rainurée d'une coquille de Saint-Jacques. Et bientôt machinalement, accablé par la morne journée et la perspective d'un triste lendemain, je portai à mes

12. Ibidem, p. 249. 
lèvres une cuillère de thé où j'avais laissé s'amollir un morceau de madeleine. Mais à l'instant même où la gorgée mêlée des miettes du gâteau toucha mon palais, je tressaillis, attentif à ce qui se passait d'extraordinaire en moi. Un plaisir délicieux m'avait envahi, isolé sans la notion de sa cause...» ${ }^{13}$.

Del sabor de la madalena, Proust va a tener el recuerdo del pasado. A partir de este momento, su infancia, Combray, aparecerán con gran claridad.

«...Et tout d'un coup le souvenir m'est apparu. Ce goût c'était celui du petit morceau de madeleine que le dimanche matin à Combray, quand j'allais lui dire bonjour dans sa chambre, ma tante Léonie m'offrait après l'avoir trempé dans son infusion de thé ou tilleul...» ${ }^{14}$.

Estos momentos privilegiados van a sucederse

«Mais au moment où... je posai mon pied sur un pavé qui était un peu moins élevé que le précédent, tout mon découragement, s'évanouit devant la même facilité qu'à divers époques de ma vie... Et presque tout de suite, je la reconnus, c'était Venise dont mes efforts pour la décrire... et que la sensation que j'avais ressentie jadis sur deux dalles inégales du baptistère de SaintMarc m'avait rendue avec toutes les autres sensations jointes ce jour-là à cette sensation-là...» ${ }^{15}$

Al principio Proust se sentirá azorado; después los recuerdos se acumularán. Por este proceso Balbec va a encontrarse al lado de Venise.

«...La serviette que j'avais prise pour m'essuyer la bouche avait précisément le genre de raideur et d'empesé de celle avec laquelle j'avais eu tant de peine à me sécher devant la fenêtre, le premier jour de mon arrivée à Balbec... ${ }^{16}$

El «pavé», la madalena, la cuchara, son los instrumentos por los que la memoria involuntaria hace resurgir en el presente un momento de la vida profunda de los seres. Estos momentos son resucitados gracias a las reminiscencias.

Proust distingue dos tipos de signos sensibles:

13. Ibidem, p. 55.

14. Ibidem, p. 57 .

15. «Le temps retrouvé.» (A la recherche du temps perdu VIII.) Gallimard, pp. 221-222.

16. Ibidem, p. 223. 
- Las reminiscencias (facultad del espíritu que trae a la memoria recuerdos pasados).

—Los descubrimientos (verdades obtenidas con ayuda de figuras).

Para Proust las reminiscencias son recuerdos involuntarios muy importantes, le ayudan a encontrar el tiempo perdido ${ }^{17}$.

Su mecanismo es asociativo identificando el pasado con el presente. La sensación atrae la esencia del recuerdo que tiene una continuidad en el tiempo.

La angustia de Proust por encontrar el pasado, su fracaso con la memoria voluntaria y la impotencia de la sensación, es compensada cuando la memoria involuntaria le trae los recuerdos completos, siente que su esfuerzo ha servido para algo y puede salvarlos para la eternidad.

«Quand au moment où j'ouvrais distraitement l'un d'eux: François le Champi de George Sand, je me sentis désagréablement frappé comme par quelque impression trop en désacord avec mes pensées actuelles jusqu'au moment où avec une émotion qui allait qusqu'à me faire pleurer, je reconnus combien cette impression était d'accord avec elle... le souvenir de ce qui m'avait semblé inexplicable dans le sujet de François le Champi tandis que maman me lisait le livre... c'était une impression bien ancienne où mes souvenirs d'enfance et de famille étaient tendrement mêlés...» ${ }^{18}$

El recuerdo involuntario, se identifica con nosotros, es como el fefenómeno de «déjà vu» y de sus profundidades aparece el momento deseado.

En todo este proceso, la sensación ocupa un lugar importante, igual que la Naturaleza. Al contemplar un paisaje, se siente invadido por una creciente dicha que traerá consigo el recuerdo de unos momentos pasados.

«Tout le bonbeur, tout le trésor de ces heures se précipitèrent à la suite de cette sensation reconnue et ce jour-là lui-même revécut pour moi» ${ }^{19}$.

Jean Santeuil, por ejemplo, encuentra su infancia gracias al perfume de las lilas.

17. "Jean Santeuil.» (Précédé de Les plaisirs et les jours.) Bibliothèque de la Pléiade. N.R.F. Edit. Gallimard, 1971, pp. 897-898.

18. “Le temps retrouvé.» (A la recherche du temps perdu VIII.) Gallimard, pp. 241-242.

19. “Contre Sainte-Beuve.» N.R.F. Edit. Idées-Gillimard, 1954, p. 58. 
Lo maravilloso en la evolución del Recuerdo en Proust, es la identificación del lector con todas sus experiencias. El lector aprende a ser sensible a los signos exteriores y a saberlos interpretar.

Elizabeth R. Jackson ${ }^{20}$ con respecto a la evolución de la memoria en Proust, considera, como elementos esenciales, la sensación y la afectividad. La memoria voluntaria se opone a la memoria involuntaria, por ser razonada, en cambio la sensación es capaz de reanimar la esencia del recuerdo adormecido.

Todos estos hechos van a tener consecuencias importantes en Proust ya que la felicidad va a ser el punto culminante de su obra, conseguida gracias a la conquista del tiempo.

\section{LES OEUVRES DE MARCEL PROUST}

(A la Recherche du temps perdu»

“Du côté de chez Swan». (A la recherche du temps perdu I.) Gallimard, 1954.

(A l'ombre des jeunes filles en fleurs.» (A la recherche du temps perdu II.) Gallimard, 1954.

«Le côté de Guermantes I-II.» (A la recherche du temps perdu III-IV.) Gallimard, 1954.

"Sodome et Gomorrhe.) (A la recherche du temps perdu V.) Gallimard, 1954.

"La Prisonnière.» (A la recherche du temps perdu VI.) Gallimard, 1954.

(Albertine disparue.) (A la recherche du temps perdu VII.) Gallimard, 1954.

(Le temps retrouvé.» (A al recherche du temps perdu VIII.) Gallimard, 1954.

\section{OBRAS CONSULTADAS}

BrÉE, G., «Du temps perdu au temps retrouvé». Société d'Edition «Les Belles Lettres». Paris, 1969.

Cattavi, Georges, «Proust». Classiques du XX siècle. Edit. Universitaires. Paris, 1958.

Deleuze, Guilles, «Proust et les signes». P.U.F. Paris, 1971.

Hernández, Francisco Javier, «Proust y la realidad». Rev. «Urogallo». Septiembre, 1971.

Jackson, Elizabeth R., “L'évolution de la mémoire involontaire dans l'oeuvre de Proust». A. G. Nizet. Paris, 1966.

Mauriac, Claude, “Proust par lui-même». Edit. Seuil. Colle. «Ecrivains de toujours». 1953.

Painter, G. D., “Proust». Tome I et II. London, 1965. Traduction française. Paris, 1966. «Biographie de Proust». Revue général Belge. Bruxelles, avril, 1967. Traducido al español. Edit. Lumen. Barcelona. Alianza Editorial, 1972.

Paulhan, Frédéric, «La fonetion de la mémoire et le souvenir affectif». Alcan. Paris, 1904.

Picon, Gëtan, «Lecture de Proust». (Idées 157). Gallimard. Paris, 1968.

Pouler, Georges, «Etudes sur le temps humain». Paris. Plon, 1950. «L'espace proustien ». Gallimard. Paris, 1964.

Richard, Jean-Pierre, «Proust et le monde sensible». Aux éditions du Seuil. Paris, 1974.

20. JaCkson, Elizabeth R., “L'évolution de la mémoire involontaire dans l'oeuvre de Proust), A. G. Nizet. Paris, 1966. 